Advanced High Strength Sheet Steels 

Nina Fonstein

\section{Advanced High Strength Sheet Steels}

Physical Metallurgy, Design, Processing, and Properties

睹 Springer 


\author{
Nina Fonstein \\ Scientific Advisor, Global R\&D \\ ArcelorMittal \\ East Chicago, IN, USA
}

ISBN 978-3-319-19164-5

ISBN 978-3-319-19165-2 (eBook)

DOI 10.1007/978-3-319-19165-2

Library of Congress Control Number: 2015947817

Springer Cham Heidelberg New York Dordrecht London

(C) Springer International Publishing Switzerland 2015

This work is subject to copyright. All rights are reserved by the Publisher, whether the whole or part of the material is concerned, specifically the rights of translation, reprinting, reuse of illustrations, recitation, broadcasting, reproduction on microfilms or in any other physical way, and transmission or information storage and retrieval, electronic adaptation, computer software, or by similar or dissimilar methodology now known or hereafter developed.

The use of general descriptive names, registered names, trademarks, service marks, etc. in this publication does not imply, even in the absence of a specific statement, that such names are exempt from the relevant protective laws and regulations and therefore free for general use.

The publisher, the authors and the editors are safe to assume that the advice and information in this book are believed to be true and accurate at the date of publication. Neither the publisher nor the authors or the editors give a warranty, express or implied, with respect to the material contained herein or for any errors or omissions that may have been made.

Printed on acid-free paper

Springer International Publishing AG Switzerland is part of Springer Science+Business Media (www.springer.com) 


\section{Foreword}

A book coauthored by N.M. Fonstein and S.A. Golovanenko under the title "Dual-phase low-alloy steels" was published in 1986 in Russia. Deep and wide research conducted for various applications of dual-phase steels with ferrite-martensite structure, including intensive trials of cold-rolled sheet steels for cars and long products for fasteners, laid the foundation for this book. It reflected the results of numerous studies by graduate students and engineers of laboratory of formable steels, which was led by Dr. Fonstein, and the analysis of world literature, spanning research methods of structure investigation of multiphase steels, the relationship of parameters of the structure and mechanical properties, and the fundamentals of heat treatment and characteristics that are important for the application of these steels such as formability, weldability, fatigue, etc. It was the first and so far, it seems, the only monograph devoted to dual-phase steel. However, the extensive presented information, including industrial development, was limited to the strength levels between 500 and $700 \mathrm{MPa}$.

Later on, when Nina Fonstein and a couple of her former graduate students joined the research center of ArcelorMittal, where Nina for over 10 years led the development of steels for the automotive industry, they had to develop dual-phase steels of higher and higher strength, 780, 980, $1180 \mathrm{MPa}$, TRIP steels, new martensitic steels, complex phase steels, to explore ways of various structural approaches to meet the requirements for the third-generation steels.

This book is once again the world's first attempt to outline the fundamental features of structure and mechanical properties of all modern Advanced HighStrength Steels families. It is important not only that, in contrast to numerous works of multiple conferences on the subject, this book provides a comparative analysis and synthesis of existing literature and author's data, but also that results are summarized from the position of the researcher with the dual responsibilities for not only fundamental understanding of physical metallurgy but also for the industrial implementation of developed grades.

The volume and quality of the data interpreted in this book came about not only because of Nina's individual ability, which itself is quite remarkable, but also due to 
major contributions of the postgraduate students and young engineers of Research Center at ArcelorMittal whom Dr. N. Fonstein continues to lead. Information presented in this book is transcending geographical boundaries and fully capitalizing of the global nature of ArcelorMittal research organization with 12 centers around the world and close cooperation with Academia. It should be noted, however, that the major contribution came from North America and European Centers.

I am thoroughly convinced that the published book will be a useful reference and guiding tool for engineers engaged in the development, production, and use of AHSS, as well as students of Universities and graduate students involved in the creation of new automotive products.

VP, Head of Global R\&D, ArcelorMittal, Europe Greg Ludkovsky 


\section{Acknowledgments}

This book became possible thanks to the outstanding contributions of my graduate students and employees of the I.P. Bardin Central Research Institute of Ferrous Metallurgy in Moscow, in particular, A. Bortsov, T. Efimova, and A. Efimov, and intensive investigations of ArcelorMittal Global Research Center in East Chicago and especially by Olga Girina, Oleg Yakubovsky, Hyun-Jo Jun, and Rongjie Song, as well as due to creative atmosphere of the Center and the constant support of its leaders Greg Ludkovsky, Debanshu Bhattacharya, and Narayan Pottore.

Sincere thanks to John Speer for fruitful discussion of the book contents and Sebastien Allain for helpful advice during the preparation of a chapter on TWIP steels.

And last but not the least - special thanks to my husband and a supporter for my entire life for his help and patience. 



\section{Contents}

1 Evolution of Strength of Automotive Steels to Meet

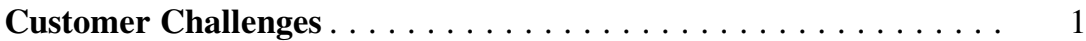

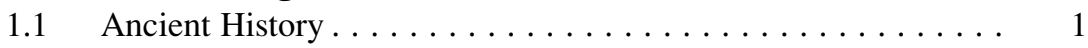

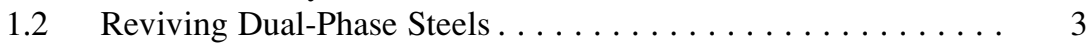

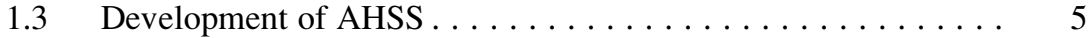

1.4 Nowadays. . . . . . . . . . . . . . . . . . . 7

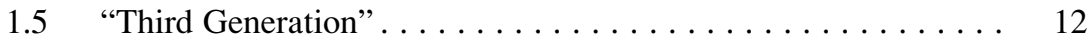

1.5.1 Carbide-Free Bainitic Steel . . . . . . . . . . . . . . 13

1.5.2 Medium Mn Steels . . . . . . . . . . . . . . . 13

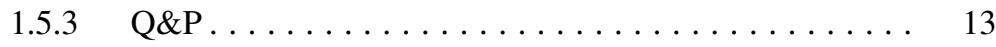

References........................... 14

2 Main Features of Heat Treatment

from Intercritical Region . . . . . . . . . . . . . . . . . . . 17

2.1 Main Characteristics of Continuous

Annealing/Coating Lines . . . . . . . . . . . . . . . . . . . . 19

2.2 Austenite Formation During Heating and Soaking

of Low-Carbon Steel in the Intercritical

Temperature Range . . . . . . . . . . . . . . . . . 21

2.2.1 Nucleation of Austenite . . . . . . . . . . . 21

2.2.2 Growth of Austenite . . . . . . . . . . . . . 24

2.3 Microstructural Changes in the Ferrite Constituent . . . . . . . . 39

2.3.1 Recrystallization of Ferrite . . . . . . . . . . . . 39

2.3.2 Precipitation of Dispersed Particles . . . . . . . . . . 40

2.4 Partitioning of Interstitial and Alloying Elements . . . . . . . . . 42

2.5 Transformations of Austenite During Cooling

from the Intercritical Region . . . . . . . . . . . . . . . 44

2.5.1 Features of Transformations of Austenite

During Cooling from the Intercritical

Temperature Range . . . . . . . . . . . . . . 45 
2.5.2 The Effect of Annealing Temperature in the Two-Phase Region . . . . . . . . . . . . . 50

2.5.3 Effect of Cooling Rate . . . . . . . . . . . . . . 50

2.6 Obtaining of As-Rolled Dual-Phase Microstructure

by Cooling of Deformed Austenite . . . . . . . . . . . . . 53

2.7 Austempering Annealing Cycle . . . . . . . . . . . . . . 54

2.8 Tempering of Ferrite-Martensite Mixture . . . . . . . . . . . . 56

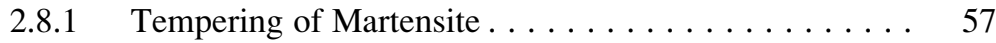

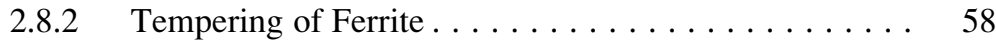

2.8.3 Decomposition of Retained Austenite . . . . . . . . . 59

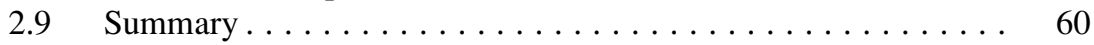

References............................. 61

3 Effect of Structure on Mechanical Properties

of Dual-Phase Steels . . . . . . . . . . . . . . . . . . . . . . 67

3.1 Existing Models of the Tensile Behavior of Heterogeneous Materials . . . . . . . . . . . . . . . . 68

3.2 Strength Characteristics of Dual-Phase Steels . . . . . . . . . . 77

3.2.1 Resistance of Dual-Phase Microstructure to Microplastic Deformation . . . . . . . . . . . . . . . 78

3.2.2 Yield Strength of Dual-Phase Steels . . . . . . . . . . . 80

3.2 .3 Tensile Strength . . . . . . . . . . . . . . . . . 91

3.3 Strain Hardening of Dual-Phase Steels . . . . . . . . . . . . . . . 97

3.3.1 Characteristics of Strain Hardening . . . . . . . . . . . 97

3.3.2 Models of Strain Hardening of Dual-Phase Steels . . . . 100

3.3.3 Experimental Data on the Effects of Microstructure Parameters on Strain-Hardening Behavior of DP Steels . . . . . . . . . . . . . . . . . 103

3.4 The Ductile Properties of Dual-Phase Steels . . . . . . . . . . . . . 109

3.4.1 Uniform Elongation . . . . . . . . . . . . . . . . . . . 109

3.4 .2 Total Elongation . . . . . . . . . . . . . . . . 111

3.4 .3 Reduction of Area . . . . . . . . . . . . . . . . 113

3.5 Quench and Strain Aging . . . . . . . . . . . . . . . 115

3.6 Tempering of Dual-Phase Steels . . . . . . . . . . . . . . . . 121

3.7 Fracture Behavior of Dual-Phase Steels . . . . . . . . . . . . . 123

3.7.1 Theoretical Concepts of Fracture of Heterogeneous Materials . . . . . . . . . . . . . . . . 124

3.7.2 Microstructural Features Controlling Fracture Initiation in Dual-Phase Steels . . . . . . . . . . . . . 126

3.7.3 Effect of Microstructure of DP Steel on Crack Propagation . . . . . . . . . . . . . . . . . 128

3.7.4 Fatigue Resistance . . . . . . . . . . . . . . . . . 130

3.7.5 Resistance of Dual-Phase Steels to Hydrogen

Embrittlement ..................... 130

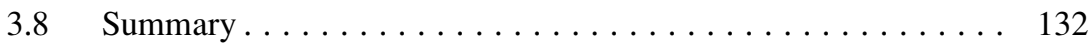

References............................ 132 


\section{The Effect of Chemical Composition on Formation} of Ferrite-Martensite Structures and Mechanical Properties of Dual-Phase Steels . . . . . . . . . . . . . . . . . . . . . . . . 139

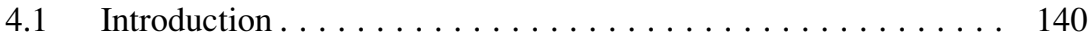

4.2 Effect of Steel Composition on Processes During Heating in the Intercritical Temperature Range . . . . . . . . . . . . . . . . . 140

4.2.1 Effect of Chemical Composition on the Volume of the Formed Austenite . . . . . . . . . . . . . . . 141

4.2 .2 Austenitization Kinetics . . . . . . . . . . . . . . . . . . . . . . . . . . . . . 144

4.2 .3 Austenite Morphology . . . . . . . . . . . . . . . . . 147

4.2.4 Recrystallization of Ferrite and Ferrite Grain Size . . . . 148

4.2.5 Effective Carbon Content in Austenite and Its Homogeneity . . . . . . . . . . . . . 150

4.3 Effect of Steel Composition on Austenite Transformation and Properties of the Formed Phases in Cooling from $\alpha+\gamma$ Region . . . . . . . . . . . . . . . . . 151

4.3.1 Hardenability of Austenite in Cooling from Intercritical Region . . . . . . . . . . . . . . 151

4.3.2 Ferrite Solid Solution . . . . . . . . . . . . . . . 163

4.3.3 Precipitation Hardening of Ferrite . . . . . . . . . . . . . . . . . . 165

4.3.4 Austenite Non-homogeneity . . . . . . . . . . . . . 166

4.3.5 Martensite Transformation Temperature . . . . . . . . . 167

4.4 Effect of Chemical Composition on Mechanical Properties of Dual-Phase Steels . . . . . . . . . . . . . . . . . . . . . . . . . . . 168

4.4.1 Tensile Properties . . . . . . . . . . . . . . . . . . . . . . . 169

4.4.2 Effect of Steel Composition on Strain Aging and Tempering Behavior of DP Steels . . . . . . . . 178

$4.5 \quad$ Summary ......................... 181

References............................. 181

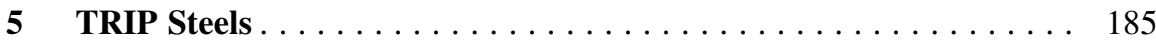

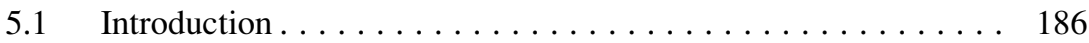

5.2 TRIP Phenomenon and the Adaptation of Metallurgical Concept to Low-Alloyed Steels . . . . . . . . . . . . . . . . . . . 187

5.3 Metallurgy of Manufacturing of TRIP Steels . . . . . . . . . . . 191

5.3.1 Phase Transformations During Heat Treatment to Produce TRIP Steels . . . . . . . . . . . . . . . . . . . 191

5.3.2 Adaptation of Heat Treatment for TRIP Steel Production to Modern Annealing and Galvanizing Lines . . . . . . . . . . . . . . . . . 192

5.3.3 Hot-Rolled TRIP Steels . . . . . . . . . . . . . . . . . . 202

5.4 Relationship of Structure and Static Mechanical Behavior of TRIP Steels . . . . . . . . . . . . . . . . . . . . . . . . . . 203

5.4.1 Effect of Structure Parameters of TRIP Steels on the Balance of Tensile Strength and Ductility . . . . . 204 
5.4.2 Effect of Amount and Stability of Austenite on Strain Hardening of TRIP Steels . . . . . . . . . . . 206

$5.4 .3 \quad$ Evaluation of Austenite Stability . . . . . . . . . . 210

5.4.4 Factors that Control Austenite Stability . . . . . . . . . . 214

5.4.5 Bake Hardening of TRIP Steels . . . . . . . . . . . . . 216

5.5 Effect of Steel Composition on Phase Transformations,

Final Microstructure, and Mechanical Properties of TRIP Steels 219

5.5.1 Effect of Ferrite-Stabilizing Elements . . . . . . . . . 221

5.5.2 Effects of Alloying Elements Enhancing

Hardenability of Austenite . . . . . . . . . . . . . . . . . 225

5.5 .3 Effect of Microalloying . . . . . . . . . . . . 228

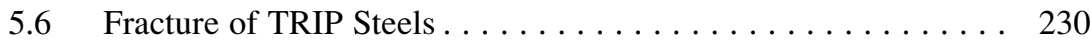

5.6.1 Energy Absorption of TRIP Steels . . . . . . . . . . 231

5.6 .2 Fatigue Behavior . . . . . . . . . . . . 233

5.6.3 Resistance to Hydrogen Embrittlement . . . . . . . . . 233

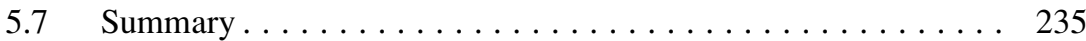

References........................... 235

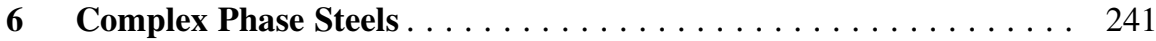

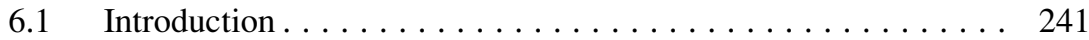

6.2 Effect of Bainite on Hole Expansion of AHSS

and "Complex Phase" Steels Concept . . . . . . . . . . . . . . 242

6.3 Microstructure-Properties Relationship of Complex

Phase Steels . . . . . . . . . . . . . . . . . . . . 246

6.4 Adaptation of Processing Parameters to Obtain

6.4.1 Effect of Chemical Composition on Phase

Transformation of Low-Carbon Steels During

Isothermal Holding and Continuous Cooling . . . . . . . 248

6.4.2 Effect of Processing Parameters . . . . . . . . . . . . . . 254

6.5 Effect of Alloying and Microalloying Elements on the

Mechanical Properties of Bainite and the Contribution

from Precipitation Hardening . . . . . . . . . . . . . . 255

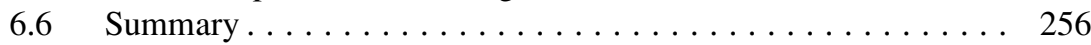

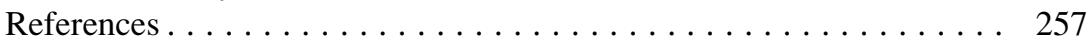

7 Martensitic Sheet Steels . . . . . . . . . . . . . . . . . . . . . . . . . . 259

$7.1 \quad$ Introduction . . . . . . . . . . . . . . . . . . . 259

7.2 Martensitic Grades for Roll Forming . . . . . . . . . . . . . . 260

7.2.1 Processing and Compositions of Annealed

Martensitic Grades . . . . . . . . . . . . . . . . . 260

7.2.2 As-Rolled Martensite . . . . . . . . . . . . . . . . . . 263

7.2.3 Effect of Martensite Tempering . . . . . . . . . . . . . . . 264

7.3 Martensite Produced by Press Hardening . . . . . . . . . . . . . 265 
7.3.1 Basic Principles of Obtaining Martensite

After Hot Stamping . . . . . . . . . . . . . . . 265

7.3.2 Development of Ultrahigh Strength Martensite for Press Hardening . . . . . . . . . . . . . . . . 266

7.3.3 Modification of Press-Hardening Technology . . . . . . . 267

7.4 Susceptibility of Martensitic Grades to Delayed Fracture . . . . . 269

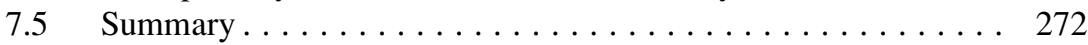

References........................ 272

8 Candidates to AHSS of Third Generation: Steels

with Carbide-Free Bainite . . . . . . . . . . . . . . . . . . . . . 275

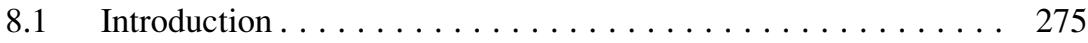

8.2 Steels with Carbide-Free Bainite or TRIP Steels

with Bainitic Ferrite: General Concept . . . . . . . . . . . . . 276

8.3 Fundamentals of CFB Steel Processing: Factors

Affecting the Kinetics of Bainitic Reaction . . . . . . . . . . . 278

8.3.1 Effect of Temperature and Time of Isothermal

Holding in Bainite Region . . . . . . . . . . . . . . 279

8.3.2 Effect of Alloying and Microalloying Elements . . . . . 280

8.3.3 Grain Size Effect. . . . . . . . . . . . . . . . . . . . 285

8.4 Factors Determining the Strength of CFB Steels . . . . . . . . . 286

8.4.1 Effect of Alloying and Microalloying Elements . . . . . 286

8.4 .2 Bainite Morphology . . . . . . . . . . . . . . . . . 289

$8.4 .3 \quad$ Fresh Martensite . . . . . . . . . . . . . . . . . . 291

8.5 Effects of Parameters of Retained Austenite

on Ductility and Localized Fracture . . . . . . . . . . . . . . . 291

8.6 Summary .......................... 293

References........................... 293

9 Candidates for the Third Generation: Medium Mn Steels . . . . . . . 297

9.1 Introduction . . . . . . . . . . . . . . . . . . . . . . . . . 297

9.2 Parameters Affecting the Properties of Mn Steels . . . . . . . . . 299

9.2.1 Effects of Temperatures and Time of Intercritical

Annealing . . . . . . . . . . . . . . . . . . . . 299

9.2.2 Effect of Volume Fraction of Retained Austenite and Its Stability on the Properties of Medium

Mn Steels . . . . . . . . . . . . . . . . . . . . . . . . . 302

9.2.3 Effect of Manganese . . . . . . . . . . . . . . . . . . 304

9.3 Localized Deformation and Strain Hardening

in Medium Mn Steels . . . . . . . . . . . . . . . . . . . . . . . 305

9.4 Effect of Initial Microstructure and Austenite Reverted

Transformation on the Evolution of Microstructure

and Mechanical Properties of Medium Mn Steels . . . . . . . . . 308

9.5 Effect of Alloying and Microalloying on Mechanical

Behavior of Medium Mn Steels . . . . . . . . . . . . . . . . . . . 314 
9.6 On the Stability of Retained Austenite in Medium

Mn TRIP Steels . . . . . . . . . . . . . . . . . . . . . . . . . . 316

9.6.1 Effect of Carbon Content . . . . . . . . . . . . 318

9.6 .2 Effect of $\mathrm{Mn} \ldots \ldots \ldots \ldots \ldots \ldots$

9.6.3 Effect of Austenite Grain Size . . . . . . . . . . . . . . 320

$9.7 \quad$ Summary . . . . . . . . . . . . . . . . . . . . 323

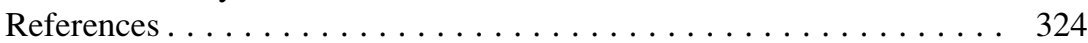

10 Candidates for Third-Generation Steels:

Q\&P Processed Steels . . . . . . . . . . . . . . . . . . . . . . . . . . 327

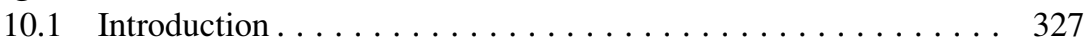

10.2 The Fundamentals of Q\&P Process . . . . . . . . . . . . . 328

10.3 Microstructure Evolution During Q\&P Process . . . . . . . . . . . 333

10.3.1 Morphology of Final Q\&P Microstructure . . . . . . . . 334

10.3.2 Effect of Initial Microstructure . . . . . . . . . . . 336

10.3.3 Effect of Initial Cooling Rate . . . . . . . . . . . . . . 338

10.3.4 Effect of Quenching Temperature . . . . . . . . . . 339

10.3.5 Bainitic Reaction During Q\&P Process . . . . . . . . . . 343

10.3.6 Effect of Partitioning Time . . . . . . . . . . . . 345

10.3.7 Effect of Partitioning Temperature . . . . . . . . . . . 349

10.4 Effect of Alloying and Microalloying Elements . . . . . . . . . . 350

10.5 On Stability of Retained Austenite in Q\&P Process . . . . . . . . . 354

10.6 Relationship Between Microstructure and Properties of Q\&P Steels . . . . . . . . . . . . . . . . . . . . . 357

10.6.1 Combination of Strength and Ductility . . . . . . . . 357

10.6.2 Strain Hardening Rate . . . . . . . . . . . . . . . . . . . . . . . . . . . . . . . . . . . . . . . . . .

10.6.3 Hole Expansion . . . . . . . . . . . . . . . . . 359

10.7 Modifications of Q\&P Thermal Cycles . . . . . . . . . . . . 361

10.7.1 Alternative Designs of Q\&P Process . . . . . . . . . . 361

10.7.2 Post-tempering of Q\&P Processed Steels . . . . . . . . . . 362

10.7.3 Application of Q\&P Approach for Hot Stamping . . . . 362

10.7.4 Q\&P During Hot Rolling . . . . . . . . . . . . . . 363

10.7.5 Q\&P Process with Quenching at Room

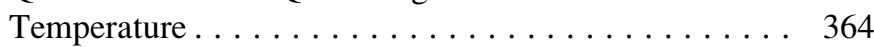

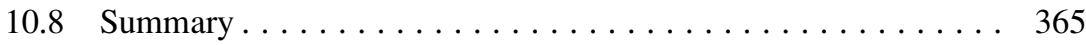

References.......................... 365

11 Austenitic Steels with TWIP Effect . . . . . . . . . . . . . . . 369

11.1 Introduction . . . . . . . . . . . . . . . . . . 369

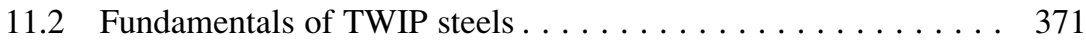

11.2.1 The Role of SFE . . . . . . . . . . . . . . . 371

11.2.2 Deformation Mechanisms of TWIP Steels . . . . . . . . 372

11.2.3 Stress-Strain Response and Localization of Deformation . . . . . . . . . . . . . . . . . 374 
11.2.4 Strain Hardening of TWIP Steels . . . . . . . . . . . . 378

11.2.5 Effect of Grain Size on Mechanical Behavior of TWIP Steels . . . . . . . . . . . . . . . . . 380

11.3 Effect of Alloying/Microalloying on Microstructure

and Properties of TWIP Steels . . . . . . . . . . . . . . . . 382

11.4 Delayed Fracture . . . . . . . . . . . . . . . . . . . . . . . . 389

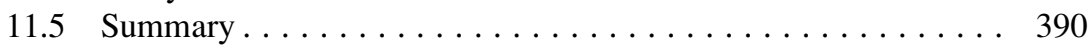

References.............................. 390

Index . . . . . . . . . . . . . . . . . . . . . . . . . . . . . 393 



\section{About the Author}

Dr. Nina Fonstein is currently a scientific advisor of automotive product development group, Global R\&D, ArcelorMittal, in East Chicago labs, USA, being for more than 10 years the manager of that group, leading investigations, development, and commercialization of various grades of AHSS. Before joining ArcelorMittal in 1999, she had been working in the I.P. Bardin Central Research Institute of Ferrous Metallurgy in Moscow, Russia, as a senior research associate and later as a head of the laboratory of formable steels working on dual-phase steels since 1979 and on TRIP steels since 1988. She graduated from the Moscow Institute of Steel and Alloys and holds Ph.D. in solid state physics from I.P. Bardin Central Research Institute of Ferrous Metallurgy (1968) and Dr. Science degree in physical metallurgy from Moscow Institute of Steel and Alloys (1986) as well as the title of Professor from the Supreme Attestation Commission of Russian Federation (1990). She is the author of the book "Dual-phase low alloyed steels" (in Russian) and more than 100 publications in English. She has supervised $16 \mathrm{PhD}$ students in Russia and is supervising PhD students-employees of ArcelorMittal. 



\section{List of Abbreviations}
AHSS Advanced high strength steels
B Bainite
Bcc Body centered cubic lattice
Bct Body centered tetragonal lattice
BH Bake hardening
BIW Body in white
CAL Continuous annealing line
CCT Continuous cooling transformation
$\mathrm{CE} \quad$ Carbon equivalent
CFB Carbide free bainite
CGL Continuous galvanizing line
CP Complex phase steels
CR Cold rolled
DP Dual phase steels
EBSD Electron back scattering diffraction
F Ferrite
Fcc Face centered cubic lattice
GJC Gas jet cooling temperature
HE Hole expansion
HER Hole expanding ratio
HR Hot rolled
HSLA High strength low alloyed steels
IBT Isothermal bainitic transformation
IQ Image quality
LOM Light optical microscopy
MP Multi-phase steels
P Pearlite
PAGS Prior austenite grain size
PHS Press hardening steels
PM Partial martensitic steels (DP steels with \%martensite $\geq 50$ )
Q\&P Quenching and partitioning 
Q\&T Quenching and tempering

RA Retained austenite

RA Reduction of area

RD Rolling direction

ReX Recrystallization

RT Room temperature

SEM Scanning electron microscopy

SS Stress-strain curve

TBF Trip steels with bainiticferrite

TD Transverse direction

TE Total elongation

TEM Transmission electron microscopy

TRIP Transformation induced plasticity

TS Tensile strength

TTT Time temperature transformation

UE Uniform elongation

UFG Ultra fine grains

ULC Ultra low carbon

UTS Ultimate tensile strength

WH Work hardening

wt $\%$ Weight percent

XRD $\mathrm{X}$ ray diffraction

YPE Yield point elongation

YS Yield strength 


\section{List of Symbols}

$\Delta G \quad$ Mechanical driving force

$A_{\mathrm{c} 1} \quad$ Temperature at which austenite formation starts during heating

Ac3 Temperature at which austenite formation is completed during heating

$A_{\mathrm{e} 1} \quad$ Equilibrium temperature for the lower boundary of the $\alpha+\gamma$ range

Ae3 Equilibrium temperature for the upper boundary of the $\alpha+\gamma$ range

Ar1 Temperature at which austenite disappears during cooling

Ar3 Temperature at which austenite starts to transform during cooling

$B_{\mathrm{S}} \quad$ Bainite start temperature

$C_{\mathrm{M}} \quad$ Martensite lattice parameter

$C_{\text {tot }} \quad$ Total carbon content [wt $\%$ in steel

$C_{\alpha} \quad$ Ferrite $C$ content [wt $\%$ in the final microstructure

$C \gamma \quad$ Austenite $C$ content [wt $\%$ ]

$f_{\mathrm{B}} \quad$ Bainitic ferrite fraction in the final microstructure

$f_{\mathrm{M}} \quad$ Martensite volume fraction

$f_{\alpha} \quad$ Ferrite fraction in the final microstructure

$f_{\gamma} \quad$ Austenite volume fraction

$M_{\mathrm{d}} \quad$ Temperature above which austenite is stable and no deformation-induced transformation to martensite takes place

$M_{\mathrm{F}} \quad$ End of martensitic transformation

$M_{\mathrm{S}} \quad$ Martensite start temperature

$M_{\mathrm{S}}{ }^{\sigma} \quad$ Temperature at which the mode of transformation of austenite to martensite changes from stress-assisted to strain-induced

$n \quad$ Strain hardening coefficient

$v \quad$ Velocity

$V_{\mathrm{M}} \quad$ Martensite volume fraction in percentage in the final microstructure

$V_{\gamma r e t}$ Retained Austenite volume fraction in percentage in the final microstructure

YS Yield stress

$\alpha \quad \alpha$-phase, ferrite

$\alpha^{\prime} \quad$ Martensite

$\gamma \quad$ Austenite 
$\gamma_{\text {res }} \quad$ Residual austenite in the process of transformation

$\varepsilon \quad$ True strain

$\rho \quad$ Dislocation density

$\sigma \quad$ True stress 